\title{
Testing of Patient Sample or Reference Material Using Manufacturer's Device
}

National Cancer Institute

\section{Source}

National Cancer Institute. Testing of Patient Sample or Reference Material Using

Manufacturer's Device. NCI Thesaurus. Code C139452.

The investigation employed relevant empirical testing of a patient sample or reference material using the device (usually an IVD) involved in the reported adverse event in order to support the identification of possible causes for the adverse event. Relevant testing would typically be based on test methods used for evaluating safety and performance as described in the latest relevant standards. 